\title{
An efficient predictive current controller with adaptive parameter estimation in $3-\Phi$ inverter
}

\author{
Haddar Mabrouk, Allaoua Boumediene \\ Smart Grids \& Renewable Energy (SGRE) Laboratory, University of Tahri Mohammed, Bechar, Algeria
}

\section{Article Info}

Article history:

Received Dec 1, 2020

Revised Feb 14, 2021

Accepted Mar 19, 2021

\section{Keywords:}

Filter

Grid-connected

Inverter

MRAS observer

Predictive control

\section{Corresponding Author:}

Haddar Mabrouk

Department of Electrical Engineering

SGRE Laboratory, University of Tahri Mohammed, Bechar, Algeria

B.P 417 route kenadsa 08000, Bechar, Algeria

Email: haddar.mabrouk@univ-bechar.dz

\begin{abstract}
In this paper, a detail design and description of a predictive current control scheme are adopted for three-phase grid-connected two-level inverter and its application in wind energy conversion systems. Despite its advantages, the predictive current controller is very sensitive to parameter variations which could eventually affected on system stability. To solve this problem, an estimation technique proposed to identify the value of harmonic filter parameter based on Model reference adaptive system (MRAS). Lyapunov stability theory is selected to guarantee a robust adaptation and stable response over large system parameter variation. The simulation results shows the efficiency of the proposed techniques to improve the current tracking performance.
\end{abstract}

This is an open access article under the CC BY-SA license.

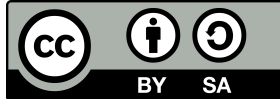

\section{INTRODUCTION}

In recent years, the grid-connected inverters have made a giant strides in the various applications of industries and renewable energies, that embody by introduce a new concepts of advanced control in detriment to other conventional controls. The grid-connected inverters is widely used in wind energy systems. The simplified structure of the grid-connected inverters is illustrated in Figure 1. Where, it's possible to replace the maximum amount of power that can be withdrawn from the wind turbine, generator, and rectifier flowed through the inverter by adequate variable DC-current source without causing any damage in system caracteristic [1]-[6].

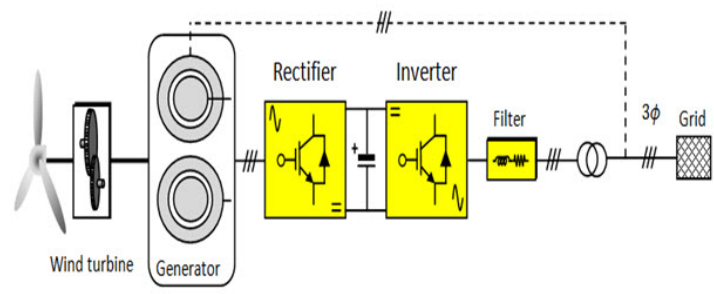

(a)

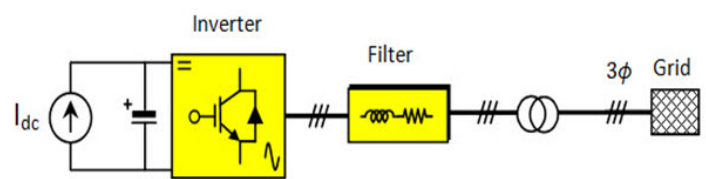

(b)

Figure 1. Grid-connected inverter in a wind energy concersion system,

(a) General structure, (b) Simplified structure 
On the other side, The progress of the micro processor unit allowed the possibility to improve the controllers design with very short sampling time and good performance. The model predictive control ( MPC) is one of the most important milestones of development, as it recently occupied a large part of studies and the researchers' effort as promise control methods because of its: ( 1 simple theory concept, $(2$ easy to implement (3 flexible and promising for digital control, (4 fast dynamic response, [2] ,[3]. However, despite of its advantages, the MPC is sensitive to the system parameter variations during the operating conditions. This results of perturbations influences on the overall stability of the system, which makes MPC need to adaptation or estimation algorithm [7]. The MPC applied for power converters and electrical drives include two main categories: Continuous Control Set MPC with a modulation stage and Finite Control Set MPC (FCS-MPC) without a modulation stage [8], [9]. In FCS-MPC, the control objectives in cost function may be either main or additional [7]-[11], the first one using physics quantities such as current, voltage, power, torque, etc. It evaluates error tracking between any predicted variable value and its reference. While the second one is considering as sub-objectives control for example switching frequency reduce. The additional control objective multiplying by suitable values of weighting factors witch's reflecting its importance in optimization criteria. The algorithm of FCS-MPC minimizes the cost function and applies the generated switching signal at end each the sampling time directly on power converter [11], [12].

The robustness of FSC-MPC against parameter variations still major concern in many studies [12]. Addressing the issue, a many control strategies have been proposed to estimate the parameters variable in power converter applications. In [9], an analytical approach is proposed to exam the influence of model parametric uncertainties on the prediction of FSC-MPC error for current control in three phase two-level inverter. In [13], the authors proposed adaptive observer to accurately estimate two variable: speed and flux, this observer based encoderless FCS-PTC (predictive torque control) helps keeping the stability for induction machine. The Model Reference Adaptive System (MRAS) observer is used in [14], where the authors estimate line inductance to improve robustness for sensorless predictive control of Active front End (AFE) rectifiers. In [15], a control scheme based on a computationally finite-set model predictive power control (FS-MPPC) for grid-connected photovoltaic systems is proposed, the stability of (FS-MPPC) against inductance variation is verified by means of novel online finite-set model inductance estimation technique. In [16], an extended Kalman filter (EKF) is proposed to estimate the system parameter ( filter grid impedance) for AFE.

However, the MRAS technique has been approved to be a powerful tool for parameter estimation, the MRAS is widely used in power electronics application and motor drives system to mainly estimate: ( 1 the filter parameter [16], (2) the machine state variables (speed, flux,...) for sensorless drive systems [18], [19],...etc, but there are limited researches based on MRAS for grid-connected inverter [16]. The MRAS consists of two models, the reference one and the adaptive one. The difference between the outputs of these two models is then used in an adaptation mechanism such as lyapunov theory to adjust the parameters in the adaptive model until the response of the main two models become consistent and the tracking error converges to zero [19], [20].

On this light, the performance of predictive current controller for the On this light, the performance of predictive current controller for the three-phase grid-connected two-level inverter entirely depends on its mathematical model as well as the accuracy of the parameters that may assumed in theory constant and known but practically not so. In this paper, the filter parameters may easily affected due to the heat risen, magnetic saturation and system lifetime, etc. This paper presents a structure that combines two types of controller; the first one is a FCS-MPC witch generate a switching states for the grid-connected inverter but it is influenced by parameters variation, this could yield negative results as inaccurate prediction of the future behavior due to an incorrect system model and so the selection of the incorrect switching states. The second is a classic which relies on the MRAS observer to cope with the aforementioned drawback through a parameter estimation method based on Lyapunov stability theory. Therefore, it is possible to avoid the deterioration of the control performance. There are a few researches report on the application the MRAS observer to grid-connected inverter [17]. So, this novel structure brings great advantages such as simple control scheme, No inner control loop, and No modulator. Additionally, although the proposed estimation technique is classic, it can make the system operate robustly and independently from mathematical model.

This paper is arranged as follows: Section ( 2 discusses the system structure and modeling. Section (3 and section (4, present the theory behind the voltage oriented vector and the predictive current control strategy, respectively. The identification of the filter parameter based on MRAS observer are presented is given in Section (5. Section (6 contains The simulation results and analysis, and finally conclusions are discussed in Section $(7$. 


\section{SYSTEM STRUCTURE AND MODELING}

The conventional power circuit of a three-phase grid-connected two-level inverter applied to wind energy is modeled as shown in Figure 2. Where, a harmonic filter $\left(r_{g}, L_{g}\right)$ takes place between the grid and the inverter. The models of the three-phase inverter and grid current dynamic are briefly described in the following subsections..

\subsection{Inverter model}

The two-level inverter is composed of six bidirectional switches. Since there are three phases with two operating modes in each phase, the inverter is able to generate only $2^{3}=8$ states as different possible output voltages. The operating modes of the inverter are summarized as follows [2]:

$$
S_{x}+\bar{S}_{x}=1 \text { for } x \in\{a, b, c\}
$$

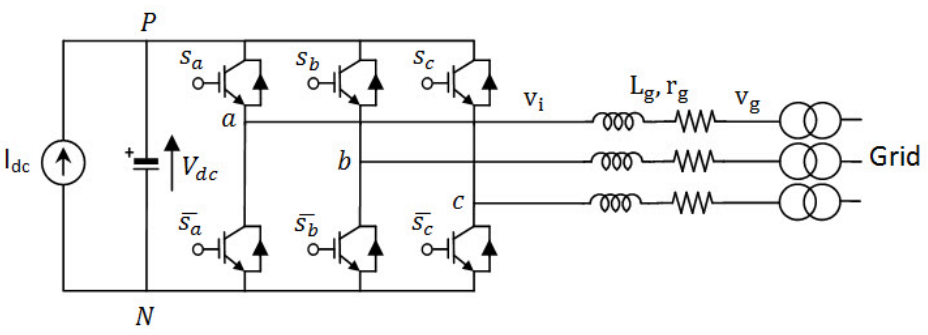

Figure 2. Topology of grid-connected two-level inverter in wind energy conversion systems

By means of the space vector tool, The output voltage generated by the inverter can expressed in terms of the different switching states by

$$
\left[\begin{array}{l}
v_{\alpha i} \\
v_{\beta i}
\end{array}\right]=V_{d c} \frac{2}{3}\left[\begin{array}{ccc}
1 & -\frac{1}{2} & -\frac{1}{2} \\
0 & \frac{\sqrt{3}}{2} & -\frac{\sqrt{3}}{2}
\end{array}\right]\left[\begin{array}{l}
S_{a} \\
S_{b} \\
S_{c}
\end{array}\right]
$$

Where $V_{d c}$ is DC link voltage, $v_{\alpha i}$ and $v_{\beta i}$ are $\alpha$ and $\beta$ component of the inverter output voltage vectors. Figure 3 shows the eight output inverter voltage vectors in space vectors corresponding the all possible switching states which including six different active voltage vectors $\left(V_{1}\right.$ to $\left.V_{6}\right)$ and two other zero vectors $\left(V_{0}\right.$ and $\left.V_{7}\right)$.

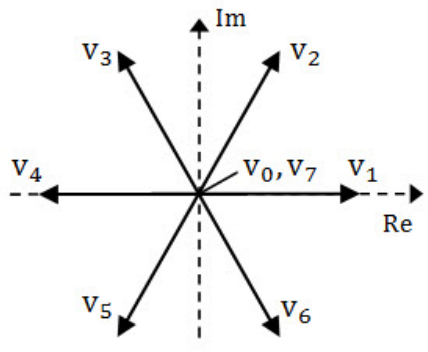

Figure 3. Space vectors generated by the inverter

The inverter voltage component expressed in the $d q$-frame rotating at angle $\theta_{g}$ can be related to the $\alpha \beta$ component by

$$
\left[\begin{array}{l}
v_{d i} \\
v_{q i}
\end{array}\right]=\left[\begin{array}{cc}
\cos \theta_{g} & \sin \theta_{g} \\
-\sin \theta_{g} & \cos \theta_{g}
\end{array}\right]\left[\begin{array}{c}
v_{\alpha i} \\
v_{\beta i}
\end{array}\right]
$$

Where $v_{d i}$ and $v_{q i}$ are $d q$-axis components of the inverter output voltage. 


\subsection{Grid current dynamic model}

The continuous-time grid current dynamic equation of three-phase grid-tied inverter can be written in the $d q$-frame as [1]-[4]

$$
\begin{aligned}
& \frac{d i_{d g}}{d t}=-\frac{r_{g}}{L_{g}} i_{d g}+\omega_{g} i_{q g}+\frac{1}{L_{g}}\left(v_{d i}-v_{d g}\right) \\
& \frac{d i_{q g}}{d t}=-\omega_{g} i_{d g}-\frac{r_{g}}{L_{g}} i_{q g}+\frac{1}{L_{g}}\left(v_{q i}-v_{q g}\right)
\end{aligned}
$$

Where $v_{d g}$ and $v_{q g}$ are $d q$-axis components of the grid voltage and $\omega_{g}$ is the angular fraquency of the grid, $r_{g}$ filter resistance and $L_{g}$ is filter inductance.

The grid active and reactive powers are expressed by [19]:

$$
\begin{aligned}
P_{g} & =\frac{3}{2}\left\{v_{d g} i_{d g}+v_{q g} i_{q g}\right\} \\
Q_{g} & =\frac{3}{2}\left\{v_{q g} i_{d g}-v_{d g} i_{q g}\right\}
\end{aligned}
$$

\section{VOLTAGE ORIENTED VECTOR (VOC)}

In the literature, the phase-locked loop (PLL) is needed not only to find the grid voltage angle $\theta_{g}$ for the grid synchronization, but also to realize the voltage oriented control (VOC). Where, the $d q$-axis components of the grid voltage is oriented to be align only with its d-axis component and eliminate the second component. That means, the active power equation and reactive power equation are simplified to [20]

$$
\begin{aligned}
P_{g} & =\frac{3}{2} v_{d g} i_{d g} \\
Q_{g} & =-\frac{3}{2} v_{d g} i_{q g}
\end{aligned}
$$

As described previously, It is noted that the $d$-axis current reference is $i_{d g}^{*}$ related to the grid active power. It can be adjusted through PI controller which maintains the measured DC-link voltage $v_{d c}$ at its given reference value $v_{d c}^{*}$, we can write

$$
i_{d g}^{*}=\left(k_{p}+\frac{k_{i}}{s}\right)\left(v_{d c}^{*}-v_{d c}\right)
$$

The $q$-axis current reference $i_{q g}^{*}$ can be calculated from reference reactive power of the grid $Q_{g}^{*}$ as

$$
i_{q g}^{*}(k)=-\frac{Q_{g}^{*}}{1.5 v_{d g}^{*}}
$$

\section{PREDICTIVE CURRENT CONTROL (PCC)}

According to the 8 switching possible states for two-level inverter, the predictive current controller exploit the discrete-time model with one-step for grid-connected inverter to predict at the next instant the future behavior of the controlled grid current. It consists of three major subsystems: extrapolation of reference currents, predictive model, and cost function minimization. At each sampling time, cost function values are calculated for all of possible commutation states, based on predefined criterion. Then, the smallest value of the cost function will be used to determine the optimal switching state applied to the inverter at the next period [2]. Approximating the grid current derivatives by [1]-[3]

$$
\frac{d i_{g}}{d t} \approx \frac{i_{g}(k+1)-i_{g}(k)}{T_{s}}
$$


The discrete-time model on $d q$-frame of grid currents at $(k+1)$ state is expressed as follows:

$$
\left[\begin{array}{c}
i_{d g}(k+1) \\
i_{q q}(k+1)
\end{array}\right]=\left[\begin{array}{cc}
1-r_{g} T_{s} / L_{g} & 0 \\
0 & 1-r_{g} T_{s} / L_{g}
\end{array}\right]\left[\begin{array}{c}
i_{d g}(k) \\
i_{q g}(k)
\end{array}\right]+\left[\begin{array}{cc}
L_{g} & 0 \\
0 & L_{g}
\end{array}\right]\left[\begin{array}{l}
v_{d i}(k)-v_{d g}(k) \\
v_{q i}(k)-v_{q g}(k)
\end{array}\right]
$$

However, the future reference of the grid current $i_{g, d q}^{*}(k+1)$ can be estimated by means of current and previous value of the reference current with the help of second-order Lagrange extrapolation as follows [2], [3].

$$
\left[\begin{array}{l}
i_{d g}^{*}(k+1) \\
i_{q q}^{*}(k+1)
\end{array}\right]=2\left[\begin{array}{l}
i_{d g}(k) \\
i_{q g}(k)
\end{array}\right]-\left[\begin{array}{l}
i_{d g}^{*}(k-1) \\
i_{q q}^{*}(k-1)
\end{array}\right]
$$

In this paper, the first target of the predictive current controller is to achieve the smallest current error between the extrapolated reference currents and the predicted current. The second target is to reduce significantly the switching frequency by adjusting the commutation number between two successive sampling instants. In situations where the switching loses are important. In brief, These all objectives can be expressed in the form of a cost function $g$ to be minimized. The cost function summarizes the desired behavior of the inverter can be obtained using the error squared such as :

$$
\begin{aligned}
g & =\left(i_{d g}^{*}(k+1)-i_{d g}(k+1)\right)^{2} \\
& +\left(i_{q g}^{*}(k+1)-i_{q g}(k+1)\right)^{2} \\
& +\lambda_{s w}(S(k)-S(k-1))^{2}
\end{aligned}
$$

Where $\lambda_{s w}$ is weighting factors for switching frequency reduction, $S(k)$ and $S(k-1)$ are the present switching state and past applied switching state respectively. Figure 4 shows the proposed predictive current controller for the grid-connected two-level inverter. In this scheme, getting the angle $\theta_{g}$ from the measured grid voltage is done via PLL method to make $v_{d g}$ equal to $V_{g}$ and also to transforme the variables measured ( $v_{g}$ and $i_{g}$ ) from $a b c$-frame to $d q$-frame. Once reference grid currents $i_{g, d q}^{*}(k)$ is calculated, the PCC procedure is established to select the optimal switching signal applied to the inverter. Moreover, the scheme involves the MRAS observer to improve the robusrness of PCC by identifying the filter parameter.

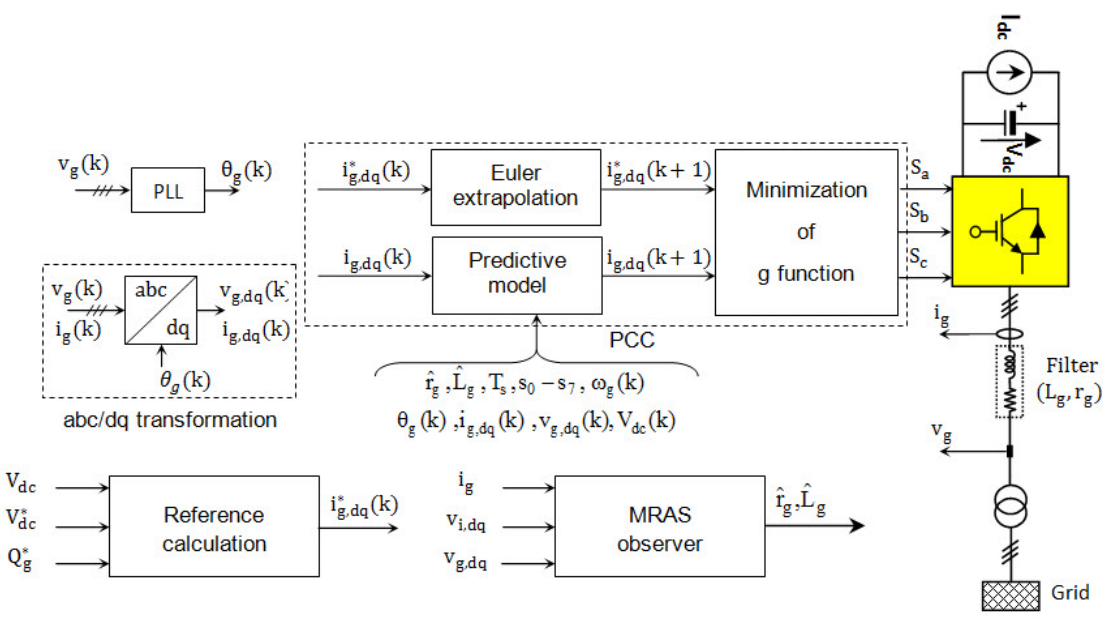

Figure 4. Proposed predictive current controller scheme for grid-connected two-level inverter.

\section{IDENTIFICATION OF THE HARMONIC FILTER PARAMETERS BASED ON MRAS}

In the real time, Both values of harmonic filter parameters (inductance and resistance) linked between the inverter and the grid are changed under the operating conditions that reduce system efficiency in term of current quality. So that, these parameters are estimated based on the model reference adaptive system (MRAS). 
Figure 5 presents the basic structure of MRAS, wich consists of three parts: a reference model , adaptive model, and an adaptive controller.

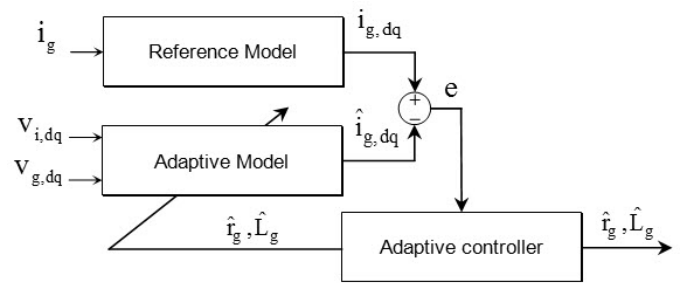

Figure 5. Basic structure of MRAS

The equation of state for reference model:

$$
\text { (4) } \Leftrightarrow \frac{d \mathbf{i}_{\mathrm{g}}}{d t}=A \mathbf{i}_{\mathrm{g}}+B u
$$

Where $\mathbf{i}_{\mathbf{g}}=\left[\begin{array}{ll}i_{d g} & i_{q g}\end{array}\right]^{T}, A=\left[\begin{array}{cc}\alpha & \omega_{g} \\ -\omega_{g} & \alpha\end{array}\right], \alpha=-\frac{r_{g}}{L_{g}}, B=-\frac{1}{L_{g}}, u=\left[\begin{array}{ll}u_{d} & u_{q}\end{array}\right]^{T}, u_{d}=v_{d i}-v_{d g}$, $u_{q}=v_{q i}-v_{q g}$

The adaptive model is given as follows:

$$
\frac{d \hat{\mathbf{i}}_{\mathbf{g}}}{d t}=A \hat{\mathbf{i}}_{\mathbf{g}}+B u
$$

Where $\hat{\mathbf{i}}_{\mathbf{g}}=\left[\begin{array}{ll}\hat{i}_{d g} & \hat{i}_{q g}\end{array}\right]^{T}, \hat{A}=\left[\begin{array}{cc}\hat{\alpha} & \omega_{g} \\ -\omega_{g} & \hat{\alpha}\end{array}\right], \hat{\alpha}=-\frac{\hat{r}_{g}}{\hat{L}_{g}}, \hat{B}=-\frac{1}{\hat{L}_{g}}, u=\left[\begin{array}{ll}u_{d} & u_{q}\end{array}\right]^{T}$

$\mathbf{i}_{\mathrm{g}}$ and $\hat{\mathbf{i}}_{\mathrm{g}}$ are the output current of reference model and adaptive model respectively. The measured grid current is tuning as the reference model witch is strongly reliant on the rated filter parameters $\left(r_{g}\right.$ and $\left.L_{g}\right)$, and the estimated grid current is tuning as the adaptive model witch uses a value of estimated filter parameters $\left(\hat{r}_{g}\right.$ and $\hat{L}_{g}$ ), and then, the output current error of two models is used by adaptive controller to adjust the parameter in adaptive controller until the identification becomes asymptotically stable and the current error approaches zero as small as possible.

The current error is defined as $\mathbf{e}=\mathbf{i}_{\mathbf{g}}-\hat{\mathbf{i}}_{\mathbf{g}}=\left[\begin{array}{ll}e_{d} & e_{q}\end{array}\right]^{T}$, the error state equation can be written:

$$
\dot{\mathbf{e}}=A \mathbf{e}+(A-\hat{A}) \hat{\mathbf{i}}_{\mathbf{g}}+(B-\hat{B}) r
$$

Letting $a I=(A-\hat{A}), b=(B-\hat{B})=\frac{1}{L_{g}}-\frac{1}{\hat{L}_{g}}, Z=\left[\hat{\mathbf{i}_{\mathbf{g}}} \quad u\right]^{T}$ and $\Delta^{T}=\left[\begin{array}{ll}a & b\end{array}\right]^{T}$

The (15) can be written as

$$
\dot{\mathbf{e}}=A \mathbf{e}+\Delta^{T} Z
$$

Considering a Lyapunov function candidate as follow:

$$
V(\mathbf{e}, t)=\frac{1}{2}\left(\mathbf{e}^{T} P \mathbf{e}+\Delta^{T} Z \Delta\right)
$$

Where $P=I_{2 \times 2}$ and $A=\left[\begin{array}{cc}\lambda_{1} & 0 \\ 0 & \lambda_{2}\end{array}\right]^{-1} \quad \lambda_{1}$ and $\lambda_{2}$ are arithmetic number.

Starting from Lyapunov stability concept, the Lyapunov function must respond the following three necessary conditions to ensure that the identification is asymptotically stable [22]-[25]:

1) $V(\mathbf{e}, t)>0$ 
2) $\dot{V}(\mathbf{e}, t)<0$

3) $V(\mathbf{e}, t) \longrightarrow \infty$ as $|\mathbf{e}| \longrightarrow \infty$.

It is evident that the first and third conditions are met. The second condition can be discussed as follows:

$$
\begin{aligned}
\dot{V}(\mathbf{e}, t) & =\frac{1}{2}\left(\dot{\mathbf{e}}^{T} P \mathbf{e}+\mathbf{e}^{T} P \dot{\mathbf{e}}+\dot{\Delta}^{T} Z \Delta+\Delta^{T} Z \dot{\Delta}\right) \\
& =\frac{1}{2}\left(\mathbf{e}^{T}\left(P A+P A^{T}\right) \mathbf{e}+a\left(\hat{i}_{d} e_{d}+\hat{i}_{q} e_{q}+\frac{\dot{a}}{\lambda_{1}}\right)\right. \\
& +b\left(u_{d} e_{d}+u_{q} e_{q}+\frac{\dot{b}}{\lambda_{2}}\right)
\end{aligned}
$$

For $P A+P A^{T}=2 \alpha I<0$ it is clear that $e^{T}\left(P A+P A^{T}\right)$ is negative definite.

The term $\dot{V}(e, t)$ must be negative definite, this yields

$$
\begin{gathered}
\frac{\dot{a}}{\lambda_{1}}+\hat{i}_{d g}\left(i_{d g}-\hat{i}_{d g}\right)+\hat{i}_{q g}\left(i_{q g}-\hat{i}_{q g}\right)=0 \\
\frac{\dot{b}}{\lambda_{2}}+u_{d}\left(i_{d g}-\hat{i}_{d g}\right)+u_{q}\left(i_{q g}-\hat{i}_{q g}\right)=0
\end{gathered}
$$

The adaptive law can be easily expressed as following:

$$
\begin{aligned}
& \frac{\hat{r}_{g}}{\hat{L}_{g}}=\frac{r_{g}}{L_{g}}-\lambda_{1} \int_{0}^{t}\left\{\hat{i}_{d g}\left(i_{d g}-\hat{i}_{d g}\right)+\hat{i}_{q g}\left(i_{q g}-\hat{i}_{q g}\right)\right\} d t \\
& \frac{1}{\hat{L}_{g}}=\frac{1}{L_{g}}+\lambda_{2} \int_{0}^{t}\left\{u_{d}\left(i_{d g}-\hat{i}_{d g}\right)+u_{q}\left(i_{q g}-\hat{i}_{q g}\right)\right\} d t
\end{aligned}
$$

\section{SIMULATION RESULTS}

To evaluate the efficiency of the considered predictive current control model with MRAS oberver for grid connected two-level inverter under various values of parameter filter, the whole simulation studies are implemented by means of MATLAB/simulink tools. The main parameters are indicated in Table 1.

Table 1. Simulation parameters

\begin{tabular}{lcr}
\hline Parameter & Nomenclature & Value \\
\hline Rated Line-to-Line Voltage $(\mathrm{rms})[\mathrm{V}]$ & $V_{g}$ & 690 \\
Rated current $(\mathrm{rms})[\mathrm{A}]$ & $I_{g}$ & 627.6 \\
Rated active power [kw] & $P_{g}$ & 750 \\
DC-link voltage [V] & $V_{d c}$ & 1220 \\
DC-link capacitor $[\mu \mathrm{F}]$ & $C_{d c}$ & 16714 \\
Filter resistance $[\mathrm{m} \Omega]$ & $r_{g}$ & 95.25 \\
Filter inductance $[\mathrm{mH}]$ & $L_{g}$ & 0.3368 \\
Sampling time $[\mu \mathrm{s}]$ & $f_{s}$ & 20 \\
Frequency of the grid $[\mathrm{Hz}]$ & $f_{g}$ & 50 \\
\hline
\end{tabular}

The results presented in three scenario:

- Ideal Case operation: In this case, the filter parameter are setting on rated values

- Non-ideal Case operation without MRAS: In this case, the parameter filter are changed to show the influence of parameter variation on whole performance of system.

- Non-ideal Case operation with MRAS: In this case, the MRAS observer is used to estimate the filter parameter and to enhance the performance of system 


\subsection{Ideal case operation}

The performance of the proposed predictive current controller scheme for three-phase grid-connected inverters considering the rated value of filter parameter is tested by applying a DC-link voltage reference $V_{d c}^{*}=$ $1220 \mathrm{~V}$, and a zero reference power reactive $Q_{g}^{*}=0$ to unitary the power factor. Figure 6 (a) shows the weighting factor impact $\lambda_{s w}$ on the grid current quality via Total Harmonic Distortion (THD) and the average switching frequency $f_{s w}$. It's clearly noted when the weighting factor is increasing, the of the grid current is changed progressively from 1.94 to $3.57 \%$, while the average switching frequency is reduced considerably from 8.86 to $3.56[\mathrm{KHz}]$. For this reason, the weighting factor can be adjusting at 1700 for operating the inverter at $f_{s w}=3.703[\mathrm{KHz}]$ and for having a suitable value of THD at $3.30 \%$.

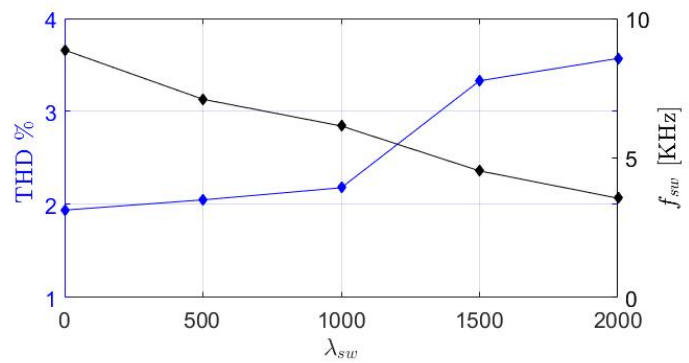

(a)

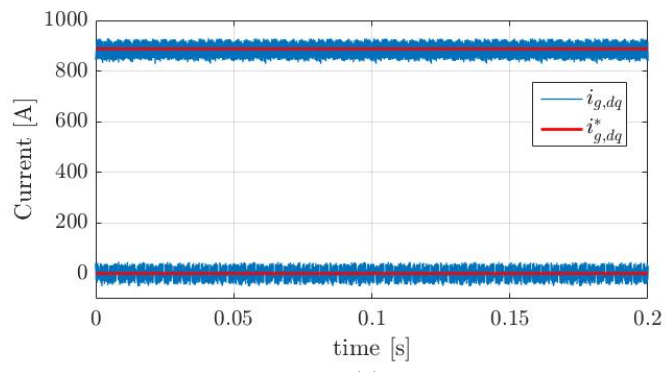

(c)

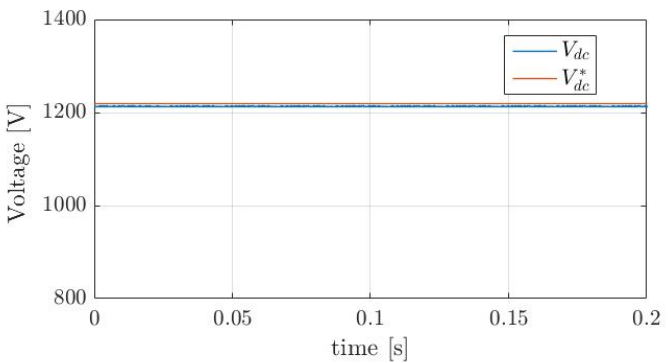

(b)

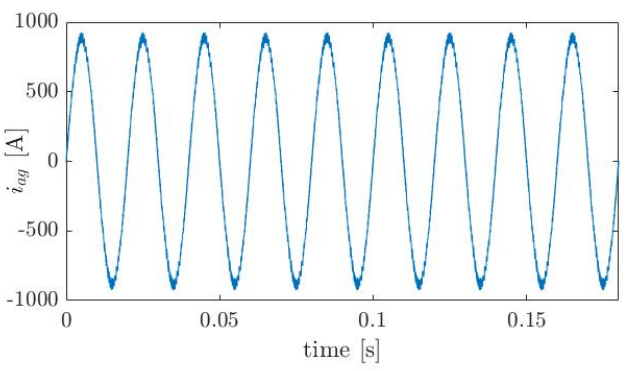

(d)

Figure 6. Simulation results for case ideal operation,

(a) THD \% and $f_{s w}$ versus $\lambda_{s w}$ variation, (b) DC-link voltage [V],

(c) $d q$-axis grid current [A] (peak), (d) waveforms of phase-a grid current $i_{a g}[\mathrm{~A}]$ (peak)

Figure 6 (b) shows the obtained simulation result where the DC-link voltage is controlled to maintain at its reference value $1200 \mathrm{~V}$ and it is stable during steady state operation. This simulated response is obtained with a PI controller having a $k_{p}=6.90$ and a $k_{i}=1.95210^{3}$. The $d q$-axis grid current components either the reference $i_{g, d q}^{*}$ or the measured $i_{g, d q}$ are tracking each other perfectly as shown in Figure 6 (c). Consequently, The amplitude of the reference $d$-axis grid current component $i_{d g}^{*}$ created from the voltage PI controller is equal to $887.5 \mathrm{~A}$ (peak). In addition, the grid-connected inverter is controlled to supply zero reactive power corresponding the zero reference $q$-axis grid current. Figure 6 (d) illustrates the waveform of a-phase grid current, where the peak value of $i_{a g}$ is equal to $i_{d g}$.

\subsection{Non-ideal case operation without MRAS}

It's the case where the variation in filter parameter has been considered as follows:

- Filter resistance and inductance are $50 \%$ lower than its nominal value

- Filter resistance and inductance is also $100 \%$ of its nominal value

- Filter resistance and inductance are $150 \%$ higher than its nominal value

These values are applying at the following moments 0.1 and 0.2 (s) respectively. Figure 7 shows the effect of parameters variation of both $r_{g}$ and $L_{g}$ on the overall performance of the controller as well as its stability. Under these conditions, it is clear to note the tracking errors between the measured values of $i_{d g}, i_{q g}$, and $V_{d c}$ and their references, which leads to unbalanced value of THD especially when both the resistance and the inductance are higher than the nominal values as presented in Figure 8. 


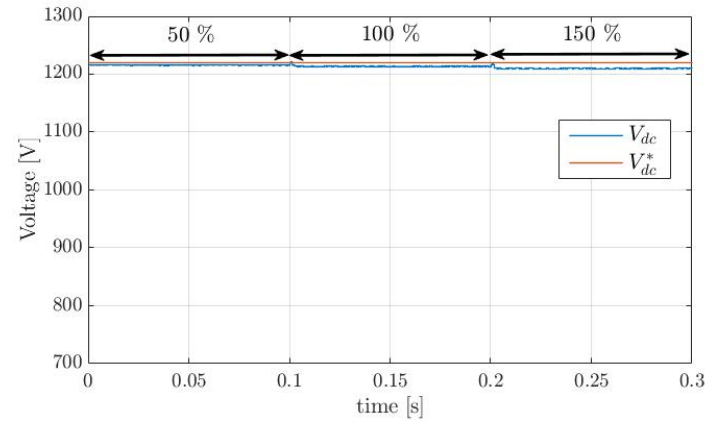

(a)

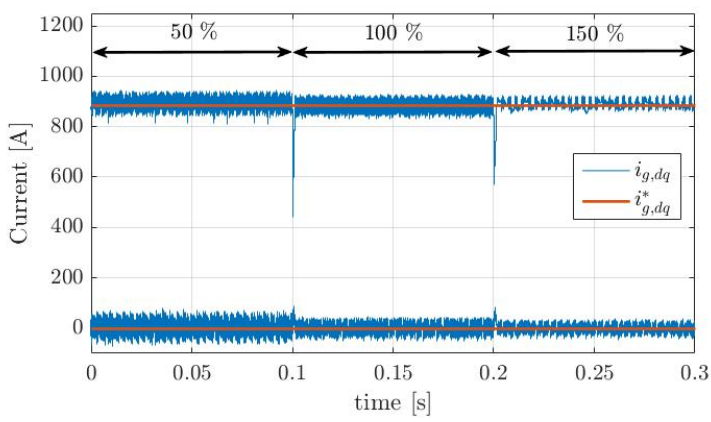

(b)

Figure 7. Simulation results for case non-ideal operation without MRAS,

(a) DC-link voltage [V], (b) $d q$-axis grid current [A] (peak).
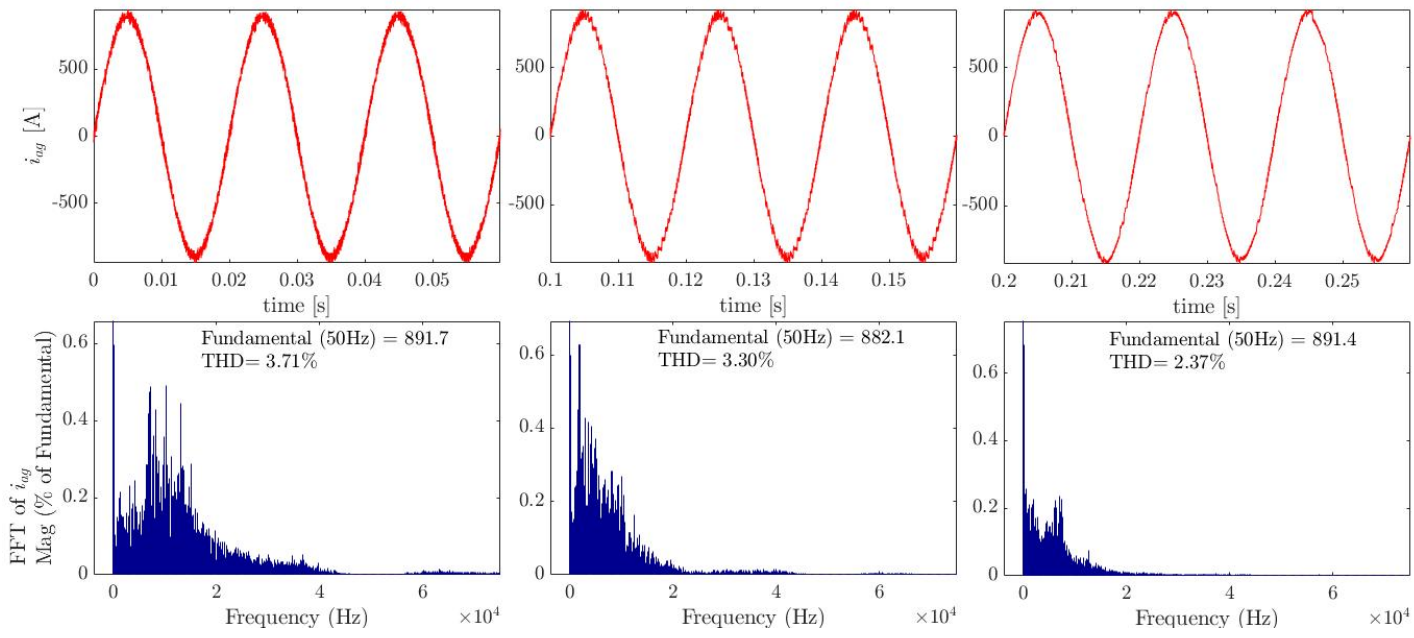

(a)

(b)

(c)

Figure 8. Simulation results explains the influence of filter parameters variation on the performance of PCC $r_{g}$ and $L_{g}$ are: (a) $50 \%$ lower than its nominal value , (b) aquals to nominal value,

(c) $150 \%$ higher than its nominal value.

\subsection{Non-ideal case operation with MRAS}

Figure 9 shows the dynamics performance of PCC scheme when the MRAS observer based on lyapunov function is enable under parameters variation. The adaptive gains are tuned using a tuning method (trial and error) to give suitable performance. After some tuning, the adaptive gains are setting as following: $\lambda_{1}=0.625$ and $\lambda_{2}=6.795$. the simulation results consists of two parts: in the first one, the filter parameters are increasing and switching from $50 \%$ of its nominal value to nominal value, and in the second one the filter parameters are decreasing and switching from $150 \%$ of its nominal value to nominal value. 

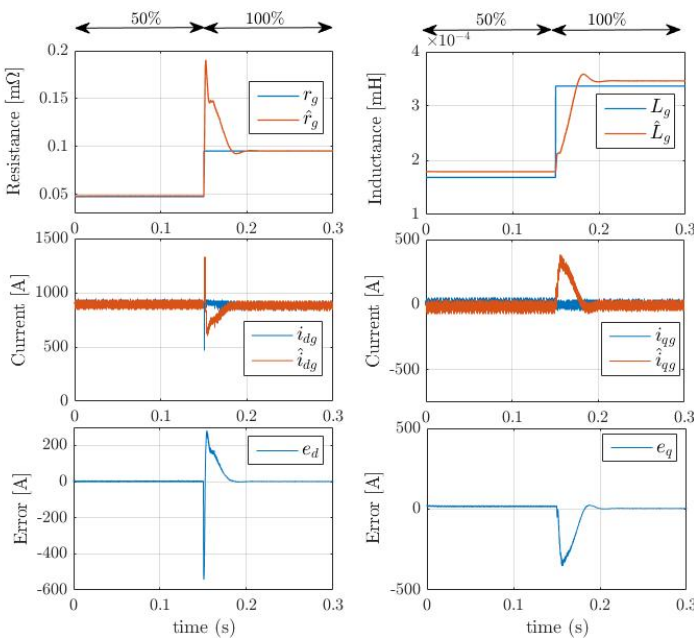

(a)
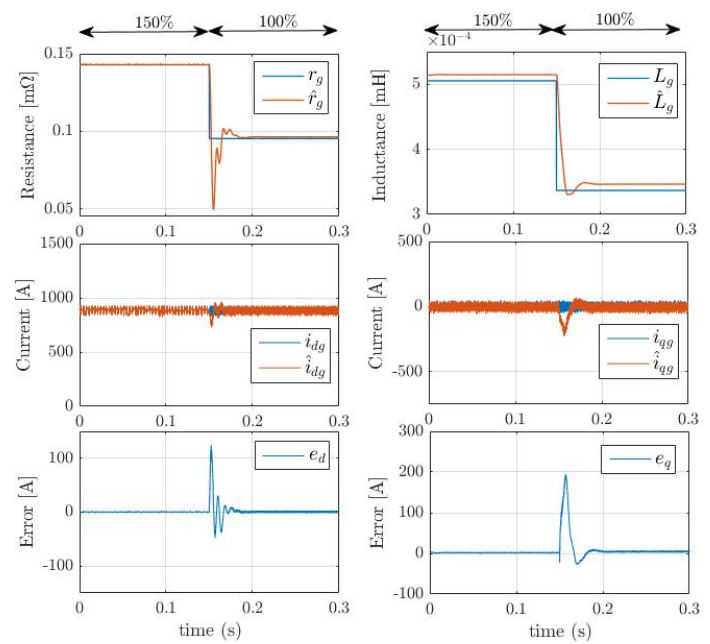

(b)

Figure 9. Simulation results for $R L$ filter parameters estimation based on MRAS on server (a) starts from $50 \%$ of its nominal value to nominal value; (b) starts from $150 \%$ of its nominal value to nominal value

The switching is applied at the moment 0.15 (s). In the both simulation, the MRAS observer track and make the estimated values converges to parameter variation. Moreover, the estimated current $\hat{\mathbf{i}}_{\mathrm{g}}$ and the measured current $\mathbf{i}_{\mathrm{g}}$ tracks each other. Despite large error at the same time where the switching is applied. the error current e converges to zero. It is worth noting that the estimate value of the filter resistance is more accurate than the estimated value of the filter inductance with steady-state estimation error in range of $1.76310^{-4}$ and $0.1 \%$ respectively.

To show the robustness of PCC controller with a MRAS observer for a three-phase grid-connected inverters, a comparison of performance can be done through two cases: The first is in agreement with the second scenario, where the filter parameters are changed in the absence of a MRAS observer, while PCC controller is operating on the normal values. As for the second case, which corresponds to the third scenario, the change of the filter parameters are in the presence of the MRAS observer, which estimates the filter parameters so that the PCC controller uses them. The comparison was done by measuring THD and $f_{s w}$, as shown in Figure 10. Although the filter parameters are changed, the MRAS observer helps the PCC controller to select a switching states that corresponds to the minimal values of $f_{s w}$ with slight difference in THD.

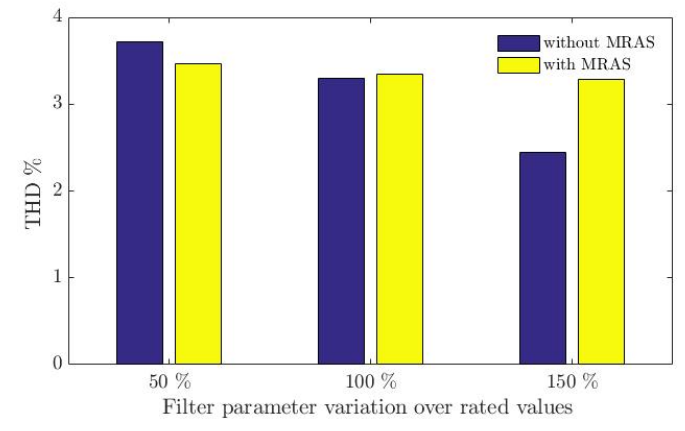

(a)

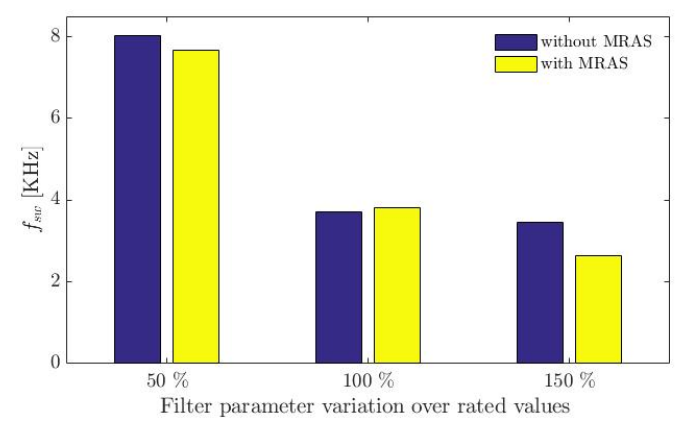

(b)

Figure 10. Comparison of system performance by measuring;

(a) THD \%; (b) $f_{s w}[\mathrm{KHz}]$. 


\section{CONCLUSION}

Sensitiveness to system parameter variations and its influences on three-phase grid-connected inverters for wind energy conversion systems has been treating in this paper. A MRAS estimator based on lyapunov function is developed to identify the RL filter parameter. the performance is verified via computer simulation, and various scenario has been studied. the simulation results show that the proposed MRAS estimator gives a good performance and the stability is guaranteed against parameter variations. In the future, a practical implementation of predictive current control model with MRAS observer for grid connected two-level inverter is planned. Moreover, a comparison between the adopted MRAS observer and others techniques such as Neural Network (NN) and Extended Kalman Filter (EKF) will be carried out.

\section{REFERENCES}

[1] B. Wu., Yongqiang Lang, Navid Zargari, and Samir Kouro, Power conversion and control of wind energy systems, New Jersey, USA: John Wiley \& Sons Inc, 2011, pp. 14-144.

[2] V. Yaramasu and B. Wu, Model predictive control of wind energy conversion systems, New Jersey, USA: John Wiley \& Sons Inc, 2016.

[3] V. Yaramasu, "Predictive control of multilevel converters for megawatt wind energy conversion systems," Ph. D. dissertation, Ryerson University, Toronto, Canada, 2014.

[4] A. Boulahia, M. Adel and H. Benalla, "Predictive power control of grid and rotor side converters in doubly fed induction generators based wind turbine," Bulletin of Electrical Engineering and Informatics (beei), vol. 2, no. 4, pp. 258-264, 2013.

[5] B. B. M. El Amine, A. Ahmed, M. B. Houari, and D. Moulud, "Modeling, simulation and control of a doublyfed induction generator for wind energy conversion systems," International Journal of Power Electronics and Drive Systems (IJPEDS), vol. 11, no. 3, pp. 1197-1210, 2020, DOI: 10.11591/ijpeds.v11.i3.pp1197-1210.

[6] Y. Barradi, K. Zazi, M. Zazi, and N. Khaldi, "Control of PMSG based variable speed wind energy conversion system connected to the grid with PI and ADRC approach," International Journal of Power Electronics and Drive Systems (IJPEDS), vol. 11, no. 2, pp. 953-968, 2020, DOI:10.11591/ijpeds.v11.i2.pp953-968.

[7] J. Rodriguez, P. Cortes, and P. C. Estay, Predictive control of power converters and electrical drives, West Sussex, UK: John Wiley \& Sons Ltd, 2012, pp. 28-33.

[8] Rodriguez, J., et al., "State of the art of finite control set model predictive control in power electronics," IEEE Transactions on Industrial Informatics, vol. 9, no. 2, pp. 1003-1016, 2013, DOI: 10.1109/TII.2012.2221469.

[9] Young, H. A., M. A. Perez and J. Rodriguez, "Analysis of finite-control-set model predictive current control with model parameter mismatch in a three-phase inverter," IEEE Transactions on Industrial Electronics, vol. 63, no. 5, pp. 3100-3107, 2016, DOI: 10.1109/TIE.2016.2515072.

[10] Cortés, P., et al., "Guidelines for weighting factors design in model predictive control of power converters and drives," 2009 IEEE International Conference on Industrial Technology, 2009, pp. 1-7, DOI: 10.1109/ICIT.2009.4939742.

[11] Kouro, S., P. Cortes, R. Vargas, U. Ammann and J. Rodriguez, "Model predictive control-A simple and powerful method to control power converters," IEEE Transactions on Industrial Electronics, vol. 56, no. 6, pp. 1826-1838, 2009, DOI: 10.1109/TIE.2008.2008349.

[12] Rodriguez, J., et al., "Predictive Current Control of a Voltage Source Inverter," IEEE Transactions on Industrial Electronics, vol. 54, no. 1, pp. 495-503, 2007, DOI: 10.1109/TIE.2006.888802.

[13] Wang, F., et al., "Finite control set model predictive torque control of induction machine with a robust adaptive observer," IEEE Transactions on Industrial Electronics, vol. 64, no. 4, pp. 2631-2641, 2017, DOI: 10.1109/TIE.2016.2529558.

[14] Mehreganfar, M. and S. A. Davari, "Sensorless predictive control method of three-phase AFE rectifier with MRAS observer for robust control," IEEE International Symposium on Predictive Control of Electrical Drives and Power Electronics (PRECEDE), 2017, pp. 107-112, DOI: 10.1109/PRECEDE.2017.8071277.

[15] Hammoud, I., K. Morsy, M. Abdelrahem, and R. Kennel, "Efficient model predictive power control with online inductance estimation for photovoltaic inverters," Electrical Engineering, vol. 102, pp. 1-14, 2019, DOI: 10.1007/s00202019-00893-8.

[16] Abdelrahem, M., C. M. Hackl, and R. Kennel, "Finite set model predictive control with on-line parameter estimation for active frond-end converters," Electrical Engineering, vol. 100, no. 3, pp. 1497-1507, 2018, DOI: 10.1007/s00202017-0606-3.

[17] Chowdhury, V. R. and J. W. Kimball, "Control of a three-phase grid-connected inverter under non-ideal grid conditions with online parameter update." IEEE Transactions on Energy Conversion, vol. 34, no. 3, pp. 1613-1622, 2019, DOI: 10.1109/TEC.2019.2898152.

[18] Abu-Rub, H., A. Iqbal, and J. Guzinski,High performance control of AC drives with MATLAB/Simulink models, John Wiley \& Sons, 2012. , 
[19] V. Yaramasu, Samir Kouro, Apparao Dekka, Salvador Alepuz, Jose Rodriguez, and Mario Duran, "Power conversion and predictive control of wind energy conversion systems," in Advanced Control and Optimization Paradigms for Wind Energy Systems: Springer, 2019, pp. 113-139, DOI: 10.1007/978-981-13-5995-8_5.

[20] D. Xu, Frede Blaabjerg, Wenjie Chen, and Nan Zhu,Advanced control of doubly fed induction generator for wind power systems, New Jersey, USA: John Wiley \& Sons Inc, 2018, pp. 99-138.

[21] Vas, P., Sensorless vector and direct torque control, Oxford Univ. Press, 1998.

[22] H. Zhang, J. Zhang and K. Guo, "An adaptive predictive current controller for Electric power steering system with Permanent Magnet Synchronous Motor," 2014 IEEE Conference and Expo Transportation Electrification Asia-Pacific (ITEC Asia-Pacific), 2014, pp. 1-6, DOI: 10.1109/ITEC-AP.2014.6941278.

[23] J.-J. E. Slotine and W. Li. Applied nonlinear control, Prentice hall Englewood Cliffs, New Jersey, pp. 40-68, 1991.

[24] K. Liu, Qiao Zhang, Zi-Qiang Zhu, Jing Zhang, An-Wen Shen, and Paul Stewart, "Comparison of two novel MRAS based strategies for identifying parameters in permanent magnet synchronous motors," International journal of automation and computing, vol. 7, no. 4, pp. 516-524, 2010, DOI: 10.1007/s11633-010-0535-3.

[25] N. T. Nguyen, "Model-reference adaptive control," in Model-Reference Adaptive Control, Advanced Textbooks in Control and Signal Processing, Springer, Cham, 2018, pp. 47-81, DOI: 10.1007/978-3-319-56393-0_5.

\section{BIOGRAPHIES OF AUTHORS}

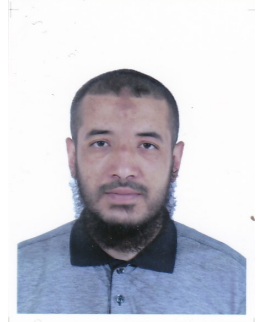

Haddar Mabrouk is received his Master's degree in "Industrial Electronics" and Bachelor's Degree in "Electronics, Electrotechnics, Automatism" (EEA) from Ferhat Abbes University, Setif, Algeria in 2012 and 2009, respectively. Actually, He is Ph.D student at Tahri Mohammed University, Bechar, Algeria. His research subject is about "modern control techniques applied on the power converters dedicated to wind energy systems", specially focused on predictive control of power converters.

His scientific interest include power converters, Advanced control and renewable energy. He is affiliated as student member with the Smart Grids \& Renewable Energies (SGRE) Laboratory, bechar, Algeria.

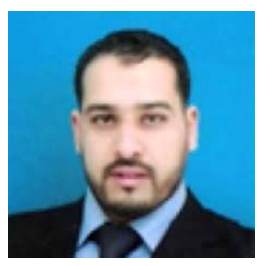

Allaoua Boumediene was born in Bechar (Algeria). He received the Ph.D degree in electrical engineering from the University of Tahri Mohamed Bechar. Currently, He is a Professor of Electrical Engineering at Faculty of Technology, Bechar, Algeria. His Research Interests Include Power Electronics, Smart Grid, Renewable Energies and Intelligent Controls for All Electric Hybrid Power Vehicles. He is the team member of intelligent energy management in the on-board systems in the smart grid \& Renewable Energies (SGRE) laboratory, bechar, Algeria. 